\title{
POLÉMICA JUDEO-CRISTIANA EN LOS REINOS HISPÁNICOS
}

\author{
Carlos Carrete Parrondo \\ Universidad de Salamanca
}

\section{RESUMEN}

En los antiguos Reinos hispánicos hubo grandes controversias entre cristianos y judíos. Las dos religiones fundamentan sus creencias en el Antiguo Testamento, pero los cristianos añaden también el Nuevo Testamento. Otra diferencia estriba en la distinta manera de interpretar la tradición textual: los cristianos emplean el método alegórico y los judíos el método literal.

\begin{abstract}
Medieval controversies between Jews and Christians in the Spanish Kingdoms. In the old spanish Kingdoms there were big controversies between Christians and Jews. The two religions based their own credencies on the Old Testament, but the Christians one also added the New Testament. Another difference lies on the different interpretation of the textual tradicion: the Christians use the allegorical method, the Jews follow the litteral one.
\end{abstract}

La controversia medieval cristiano-judía en los antiguos reinos hispánicos —en esta época aún es prematuro emplear el término 'español'-, conocida como disputa teológica entre diferentes representantes de ambos credos religiosos, ha de ser matizada con algunas observaciones para su correcta interpretación. Judíos y cristianos fundamentaban sus creencias religiosas en un solo texto revelado: la Tanah para los primeros y el Antiguo Testamento para los segundos, con idéntico contenido; pero los cristianos, además, añadieron el Nuevo Testamento sin renunciar al Antiguo. La diferencia estriba en la distinta interpretación que ambas religiones dieron al sentido de una transmisión textual: mientras que los cristianos, en líneas generales, empleaban en su exegesis un procedimiento alegórico, los judíos preferían su tradicional método literal y, por consiguiente, las diferencias podían ser fundamentales en pasajes muy concretos y a la vez esencialmente conflictivos: pueblo elegido, llegada del Mesías, concepto de virginidad referente a María. 
No conviene olvidar que la polémica ya estaba representada en la Patrística cristiana, a cuyo frente figuran San Isidoro', San Ildefonso $0^{2}$ y San Julián ${ }^{3}$, los tres precisamente nacidos en suelo hispano: la labor literaria 'adversus iudaeos' ya contaba, pues, con una dilatada tradición, aunque hay que reconocer que los fundamentos hasta entonces aducidos eran exclusivamente bíblicos y que la finalidad, en rigor, era eminentemente catequética más que polémica: pretendían instruir a los judíos para que, reconociendo sus errores en materia de fe, aceptaran la doctrina de la Iglesia como único medio para su personal salvación y, en consecuencia, se acercaran con firme sinceridad a la pila bautismal: la 'hebraica veritas' se presentaba como algo a todas luces insostenible. El presumible diálogo, en tantas ocasiones invocado, entre Sinagoga e Iglesia era en el mejor de los casos una utopía en la que nadie podía creer y que todos, por elemental convencimiento, rechazaban.

Con el trascurso de los años y merced a las conversiones al cristianismo de determinados eruditos judíos, impulsados por muy diferentes motivos, el marco de discusión se amplía al contenido del Talmud, hetereogéneo y amplio comentario judío a la Tanah (ley escrita) y a la Misnah (ley oral), en sus versiones babilónica, concluída c. 200 d.C., y palestina, finalizada tres centurias después. Y surge un nuevo y decisivo factor: la intervención de los judeoconversos en la polémica, cuyo contenido hasta entonces sólo interesaba a un reducido grupo de selectos teólogos cristianos y dirigentes espirituales judíos: el pueblo llano de ambos credos permanecía, como era natural, al margen de tan sofisticadas interpretaciones, alejadas por supuesto de los avatares más tangibles de su cotidiana realidad. Representará, en efecto, una híbrida novedad con consecuencias muy determinantes.

Pero también hay que examinar otro factor decisivo: las comunidades judías establecidas en la diáspora, y en este caso en los reinos hispánicos, eran toleradas y admitidas por la legislación civil, y en ocasiones ampliamente beneficiadas de acuerdo con la usanza de la época, con determinadas normas de carácter restrictivo. Establecer con visos de realidad si en tierras hispánicas hubo convivencia o, por el contrario, mera coexìstencia entre cristianos y judíos aún está, al menos para mí, insuficientemente clarificado: lo más probable, y de acuerdo con la documentación hasta ahora conocida, es que puedan admitirse sin ninguna dificultad -al menos documental - ambos planteamientos en determinadas zonas geográficas y en concretos ámbitos temporales, por supuesto no siempre fijos. ${ }^{+}$

Por otra parte, desde finales del s. XIII y durante casi toda la centuria siguiente se manifiestan en la Península Ibérica, junto con pestes generalizadas y drástica recesión económica

1 De fide catholica ex Veteri et Novo Testamento contra judaeos, en PL, 83, cols. 450-538, y L. Castán Lacoma: 'San Isidoro de Sevilla, apologista antijudaico', en M.C. Díaz y Díaz (ed.), Isidoriana, León 1961, pp. 445456.

2 Tratado de la perpetua virginidad de Santa Maria, introducción, traducción y notas por V. Blanco García, Zaragoza 1954.

3 De comprobatione aetatis sextae libri tres, en PL, 96, cols. 537-586.

4 D. Romano prefiere emplear el término "coexistencia', admitiendo que pudo existir en determinadas ocasiones cierta 'convivencia' (vid. su La ciencia hispanojudia, Madrid 1992, pp. 20-21). El matiz, sin duda, es de verdadera importancia. 
(sistemática ambivalencia en el valor monetario), diversos movimientos mesiánicos de carácter popular precedidos de falsos e inevitables profetas (Avila y Ayllón c. 1295): la milenaria esperanza mesiánica representaba, en definitiva, un malestar generalizado entre las comunidades judías que, ante la legislación adversa de carácter civil y eclesiástico (Concilio de Zamora de 1313 y Cortes de Palencia de 1313 y Burgos de 1315), se plantean la ancestral ilusión del retorno a tierras de Sión, donde habría de llegar el esperado Mesías que los libraría del cautiverio y destierro en países extranjeros y del contacto con sociedades mayoritarias de diferente credo religioso. Las dispersas comunidades judías asentadas en suelo hispánico no podían olvidar la sentencia que escribiera Maimónides en el ya lejano siglo XII: «Surgirá el Rey Mesías y restaurará el reino de David a su primitivo estado y original soberanía. Reconstruirá su Santuario y reunirá a todos los dispersos de Israel». ${ }^{5}$ He aquí un lema idealizado que se mantendrá durante la prolongada diáspora del pueblo judío esparcido en la amplia cuenca mediterránea.

Lo cierto es que entre los polemistas cristianos había un destacado número de origen judío y la mayor parte de ellos habían sido sintomáticamente rabinos: Semu'el el Marroquí, bautizado en 1085, ${ }^{6}$ Pablo Cristiano, protagonista frente a Rabí Moseh ben Nahmán (conocido también como Nahmánides, Rambán o Bonastruc de Porta, a quien más adelante me referiré) en la controversia celebrada en Barcelona en 1263; el burgalés Alfonso de Valladolid, antes Abner de Burgos, convertido c. $1320^{7}$ o Jerónimo de Santa Fe, antes Yehosú a ha-Lorquí, quien recibió voluntariamente el bautismo en $1412 .{ }^{8}$ A estos nombres hay que añadir los cristianos viejos Raimundo Martí, dominico del siglo XIIl y autor del Pugio fidei adversus mauros et iudaeos $;{ }^{9}$ Raimundo Lulio con su Liber predicationis contra judeos ${ }^{10}$ y fray Bernardo Oliver, autor de Contra caecitatem iudaeorum, " además de las predicaciones del valenciano fray Vicente Ferrer durante la segunda decena del siglo XV, a cuyas catequéticas reuniones los judíos tenían la obligación de acudir, muchas veces celebradas en sus propias sinagogas, y en este detalle conviene no olvidar las connotaciones sociales y religiosas.

Los representantes de las comunidadades judías también demostraron sólida formación en estas tristes polémicas orales o literarias: Moseh ha-Kohén de Tordesillas, exegeta y polemis-

5 Misneh Torah, Melakim 11.11.

6. Autor de De adientu Messiae, quem iudaei temere expectant, en PL, 149. cols. 333-368, y B. Blumenkranz, Anti-Jewish polemics and legislation in the Middle Ages: literary fiction or reality?". Journal of Jewish Studies 15 (1964) 125-140.

7 Autor de Maestro de Justicia (vid. Y.F. Baer, The cabalistic doctrine in the Christological teaching of Abner of Burgos' (en hebreo), Tarbiz 27 (1957/1958) 278-289, y J. Rosenthal, Studies and Text (en hebreo), Jerusalem 1967, 1, 324-367.

8 Autor del tratado De iudaicis erroribus ex Talmut, estudiado en profundidad por M. Orfali, Madrid 1987.

9 Vid. R. Bonfil, 'The nature of Judaism in Raymundus Martini's Pugio fidei' (en hebreo), Tarbiz 40 (1970/71) $360-375$.

10 Estudiado por J.Ma. Millás Vallicrosa, Madrid-Barcelona 1957; vid. también E. Colomer, 'Ramón Llull y el judaísmo en el marco histórico de la Edad Media hispana', Estudios Lulianos 10 (1966) 4-45.

11 Analizado por F. Cantera Burgos, Madrid-Barcelona 1963; vid. también F. Vendrell Gallostra, La obra polémica antijudaica de fray Bernardo Oliver': Sefarad 5 (1945) 303-336. 
ta del siglo XIV; ${ }^{12}$ el navarro de la misma centuria Sem Tov ben Yishaq ibn Saprut; ${ }^{13}$ el catalán Hasday Crescas (1340-1412) ${ }^{14}$ o Yosef Albó, participante en la controversia de Tortosa de $1413-1414,{ }^{15}$ a la que más adelante dedicaré alguna atención.

Ahora es preciso, para una mejor comprensión del tema que pretendo tratar, clarificar un esencial detalle no siempre bien comprendido: durante los luctuosos sucesos ocurridos en $1391,{ }^{16}$ consecuencia de las incalificables predicaciones antijudías del arcediano de Ecija Ferrán Martínez, parte del populacho cristiano - 'puebla menudo', según las crónicas cristianas de la época--, aprovechando la ausencia de arzobispo en la sede sevillana y época de regencia en la corona castellana, se lanzó incontrolado contra varias comunidades judías. La reacción del populacho no era, con mucho, la caza y destrucción física del judío, sino hacer desaparecer las conocidas como 'cartas judiegas' o, lo que es lo mismo, los documentos de préstamo que los judíos habían concedido a los cristianos durante una situación económica nada favorable. Este es un tema que necesita profunda objetividad, alejado de numerosas interpretaciones afectivas de la época y, por supuesto, del primer y directo sentido que pudiera sugerir la lectura de determinadas qinot o lamentaciones poéticas anónimas de la poesía tradional hispanohebrea compuestas a raiz de tan tristes sucesos. ${ }^{17} \mathrm{La}$ realidad es que se produjeron numerosas persecuciones antijudaicas, impulsadas por una finalidad económica -que no religiosa, conviene que repetirlo- y que motivaron la desaparición de algunas comunidades judías y numerosas conversiones al cristianismo de manera precipitada o, con otras palabras, una merma muy significativa de la población judía en cuanto a su aspecto mosaico se refiere, sólo recuperada con no poca ilusión jurídica y practicidad social mediante las taqqanot o estatutos comunitarios promulgados en Valladolid en $1432 .{ }^{18}$

Si hasta ahora la polémica judeocristiana quedaba relegada a pura y mera creación literaria, existieron tímidas confrontaciones religiosas cristianojudías en Ávila, Pamplona y acaso en Tarazona con carácter público, ${ }^{19}$ aunque hay que resaltar la celebrada en Barcelona en 1363 ,

12 Autor del Libro de la aruda de la fe y Ayuda del conocimiento (vid. Y. Shamir, Rabbi Moses ha-Kohen of Tordesillas and his book Ezer ha emunah. A chapter in the history of the Judeo-Christian controversy'; Coconut Grove 1972, 2 vols., y D.J. Lasker, Jewish philosophical polemics against Christianity in the Middle Ages, New York. 1977, pp. 14, 18 y 98-101).

13 Autor de Piedra de toque (vid. D.J. Lasker, Jewish philosophical polemics against Christianity in the Middle Ages, passim).

14 Autor de Destrucción de los principios de los cristianos (vid. y D.J. Lasker, Jewish philosophical polemics against Christianity in the Middle Ages, en especial pp. 69-74).

15 Autor del Libro de los principios (vid. D.J. Lasker, Jewish philosophical polemics against Christianity in the Middle Ages, en especial pp. 34-36).

16 Vid. Ph. Wolff, 'The 1391 Pogrom in Spain. Social crisis or not?, Past and Present 58 (1971) 4- 18.

17 Vid. H. Schirmann, 'Lamentations of the persecutions in Palestina. Africa, Spain, Germany and France' (en hebreo). Kóbes 'al rad (n.s.) 3 (1939) 23-74, y D. Pagis, 'Lamentations on the persecutions of 1391 in Spain' (en hebreo), Tarbis 37 (1967-68) 355-373.

18 Vid. Y. Moreno Koch, Fontes Iudaeorum Regni Castellae. V: De iure hispano-hebraico. Las Taqqanot de Valladolid de 1432. Un estatuto comunal renovador, Salamanca 1987.

19 Vid. D. Romano, La ciencia hispanojudia, p. 65. 
con la activa participación del venerable Rabí Moseh ben Nahmán. ${ }^{20}$ Durante cuatro días se reunieron, mediante la oficial convocatoria del rey Jaime I, representantes de las aljamas de la corona catalano-aragonesa, encabezados por Rabí Moseh ben Nahmán, y un grupo de teólogos cristianos, a cuyo frente se encontraban el judeoconverso Pablo Cristiano y Raimundo de Peñafort. En principio todos los participantes tenían el mismo derecho de exposición y réplica, pero los judíos carecían - y la diferencia no deja de ser significativa - de la posibilidad de intervenir en segunda ocasión. El tema fundamental se centraba en la figura del Mesías y, por supuesto, en su llegada, concreto punto en el que divergían ambos credos religiosos. Ante tan enfrentadas posturas ideológicas e interrumpido el debate, así opinaba Jaime I acerca de la actuación pública de Nahmánides: «Nunca he visto defender tan bien una causa tan errónea». ${ }^{21}$ Con razón D. Romano califica a estas controversias con el término 'adoctrinamiento', sin duda más en consonancia con la finalidad perseguida. ${ }^{22}$

La última de estas reuniones públicas se celebró en Tortosa desde el 7 de febrero de 1413 hasta el 13 de diciembre de $1414,{ }^{23}$ patrocinada por el antipapa aragonés Benedicto XIII, el Papa Luna, y presidida, por parte cristiana, por la antipática figura del converso Jerónimo de Santa Fe, sin duda promotor de la controversia y médico del pontífice; estaba acompañado de otros representantes sin duda más oscuros: García Alvarez de Alarcón y Andrés Bertrán. La representación judía era más numerosa: Rabí Zerahya ha-Leví (Ferrer Saladín), Rabí Mattityahu Hayishatí, Rabí Moseh Abenabez, Rabí Yosef Albó, Rabí Astruch ha-Leví, Rabí Bonyuda Yahse'el ha-Qastarí, y consta también la presencia de Rabí Profeit Durán y del poeta Selomoh Bonafed. El tema a discutir era ya conocido: ¿se habían consumado las profecías mesiánicas? o, lo que es lo mismo, ¿Cristo era el verdadero Mesías? La estratégica manipulación de diversos midrasim (comentarios homiléticos judíos) y textos talmúdicos por parte de Jerónimo de Santa Fe condujo a que la representación judía fracasara en sus pretendidos resultados. De tan atípica e innecesaria confrontación se produjeron no pocas conversiones al cris-

20 Vid. cap. II del Séfer ha-Qabbalah (Libro de la Tradición) de R. Abraham bar Selomoh de Torrutiel, en Y. Moreno Koch, Dos crónicas hispanohebreas del siglo XV. Barcelona, 1992. pp. 80-81; J. Riera i Sans y E. Feliu. Disputa de Barcelona de 1263 entre Mestre Mossé de Girona i Fra Cristià. Barcelona, 1985; A. Tostado Martín. La disputa de Barcelona 1263. Controversia judeocristiana, Salamanca, 1986, y' H. Beinart, Los judíos en España, Madrid, 1992. pp. 107-109.

21 Vid. Y. Baer, Historia de los judios en la España cristiana, Madrid, 1981, p. 125. y H. Beinart, Los judios en España. pp. 177-181. Un buen planteamiento de las controversias judeocristianas en España es el reciente de A. Meyuhas Ginio, 'La polémica cristiana adversus judaeos en España a fines de la Edad Media', El Olivo XVII/37 (1993) 5-23. Vid. también M. Orfali, 'La cuestión de la venida del Mesías en un «responsum» de Rabbí Selomó ibn Adret al cahal de Lérida', Helmantica XLIII/130-131 (1992) 203-220.

22 Vid. su La ciencia hispanojudía, p. 70, quien a continuación escribe: «en aquella época y quizás en otras muchas, cualquier 'polémica' convocada por una de las partes, y no celebrada en terreno neutral, en el fondo era inútil y con resultado previsto, inútil excepto con fines propagandísticos».

23 Vid. A. Pacios López, La disputa de Tortosa: Madrid-Barcelona, 1957, 2 vols., y J. Riera i Sans, La crònica en hebreu de la dispura de Tortosa. Barcelona, 1974. 
tianismo, acaso tres mil almas. ${ }^{2+}$ Aquí fue cuando comenzó una etapa de profunda crisis en el judaísmo hispánico, especialmente en los reinos de Aragón y Cataluña. Y, lo que fue más grave, el inicio a gran escala del problema converso, ${ }^{25}$ tema necesario analizar con la precisa objetividad documental. Sus consecuencias, según mi opinión, se adelantaron casi un siglo en la firma del decreto general de expulsión ${ }^{26}$ materializado en 1492.

\author{
Carlos Carrete Parrondo \\ Cátedra de Hebreo \\ Facultad de Filología \\ Palacio de Anaya \\ Universidad de Salamanca \\ E-37007 SALAMANCA
}

24 Vid. Y. Baer, Historia de los judios en la España cristiana, pp. 443-493, y el modélico estudio de M. Orfali, El tratado "De iudaicis erroribus ex Talmut» de Jerónimo de Santa Fe. p. 6. Sobre la supuesta falsificación de midrasim, planteada por Y. Baer, vid. A. Díez Macho, 'Acerca de los midrashim falsificados de Raimundo Martí, Sefarad 9 (1949) 167-196, y A. Pacios López, La disputa de Tortosa, I, 171-223.

25 Vid. E. Benito Ruano, Los orígenes del problema converso, Barcelona, 1976, con no pocas sugerencias, y B. Netanyahu, The Marranos of Spain fron the late XIVth to early XVIth Century: New York, 1966.

26 Vid. M. Kriegel. 'La price d' une décision: l'expulsion des juifs d'Espagne en 1492', Rerue Historique 527 (1978) 49-90; F. Márquez Villanueva. 'El problema de los conversos: cuatro puntos cardinales', en J.M. Sola-Solé (ed.), Hispania Judaica, Barcelona 1980, pp. 251-344, y E. Gutwirth, 'The Expulsion of the Jews from Spain and Jewish Historiography', en Rapoport-Albert (ed.), Jewish History: Festschrift C. Abramsky; London, 1988, pp. 141161. Testimonios judíos y cristianos coetáneos a la expulsión están reunidos en D. Raphael. The Expulsion I492. Chronicles. An Anthology of Medieval Chronicles Relating to the Expulsion of the Jens from Spain and Portugal. North Hollywood. 1992. 